\title{
Coulisses
}

Revue de théâtre

15 | Hiver 1997

Varia

\section{Une mise en scène humble et intelligente}

\section{Alain Berreta}

\section{OpenEdition}

Journals

Édition électronique

URL : http://journals.openedition.org/coulisses/5118

DOI : $10.4000 /$ coulisses. 5118

ISSN : 2546-9460

\section{Éditeur}

Presses universitaires de Franche-Comté

\section{Édition imprimée}

Date de publication : 1 janvier 1997

Pagination : 48-49

ISSN : 1150-594X

\section{Référence électronique}

Alain Berreta, « Une mise en scène humble et intelligente », Coulisses [En ligne], 15 | Hiver 1997, mis en ligne le 26 avril 2019, consulté le 31 octobre 2019. URL : http://journals.openedition.org/coulisses/ 5118 ; DOI : 10.4000/coulisses. 5118

Ce document a été généré automatiquement le 31 octobre 2019

Coulisses 


\title{
Une mise en scène humble et intelligente
}

\author{
Alain Berreta
}

Depuis sa création en 1912, L'Annonce faite à Marie n'en finit pas de subjuguer sur les scènes françaises et étrangères, les publics les plus variés. La preuve vient encore d'en être faite grâce aux représentations données par les Comédiens des Nuits de Joux, dans une mise en scène de Pierre Louis. Ce spectacle avait d'abord été présenté en plein air au début du mois d'août 1995, dans le cadre grandiose de la cour du Château de Joux dans le Doubs, qui par son architecture, nous plongeait d'emblée dans l'atmosphère médiévale de la pièce. Devant le succès populaire de ces représentations, Pierre Louis a revu sa mise en scène pour la présenter en salle au cours de l'année 1996 - en FrancheComté, puis en Suisse et dans d'autres villes françaises : Epinal, Besançon, Lyon -, et le spectacle a encore gagné en cohésion et en intensité dramatique. Le décor, réduit au minimum, c'est à dire aux quelques « acteurs permanents » chers à Claudel, le foyer, la table, la croix, a permis de focaliser l'attention sur l'essentiel, le texte. Le verbe claudélien a en effet été mis en valeur dans toutes ses richesses par la ferveur d'acteurs possédant autant leur texte qu'ils étaient possédés par lui. Signalons notamment une excellente Mara, d'abord toute en ondulations félines et à l'ironie mordante, devenue étonnamment humaine au dernier acte, un Jacques Hury vibrant d'amour, qui a su montrer que ce personnage est plus que le garçon fruste auquel on le réduit trop souvent, un père et une mère mêlant tout à tour l'émotion au comique. Violaine enfin n'est heureusement pas le personnage "sucré» que Claudel craignait tant qu'on représente, mais sait faire comprendre comment cette jeune fille heureuse renonce progressivement au bonheur humain pour accéder à la sainteté. Tous les acteurs y compris un frémissant Pierre de Craon, nous montrent très bien comment ces personnages sont animés par des passions que nous connaissons et sont attirés par un appel mystérieux, celui qui invite plus ou moins chacun de nous à chercher à se dépasser. La sobriété des décors et la judicieuse ambivalence des costumes, mêlant des souvenirs médiévaux à des éléments rustiques plus récents, achèvent de nous persuader que cette pièce dépasse largement le cadre « Moyen-Age de convention » où elle se situe pour nous concerner tous, particulièrement peut-être en cette fin de siècle. 
Bref, cette mise en scène que Pierre Louis a installée délibérément " aux lisières du théâtre, du rêve, de la mémoire et de la vie » apparaît comme une quête de nos racines et de nos aspirations profondes. L'Annonce faite à Marie, que Claudel voyait comme " glorification des réalités les plus humbles » est sans doute une des pièces qui, par son humanité concrète, est particulièrement apte à effacer la fausse image d'un Claudel austère et rigide. Mais encore faut-il que ses mises en scène, telle celle des Comédiens des Nuits de Joux, sachent se mettre, humblement et intelligemment, au service d'un texte si étonnant.

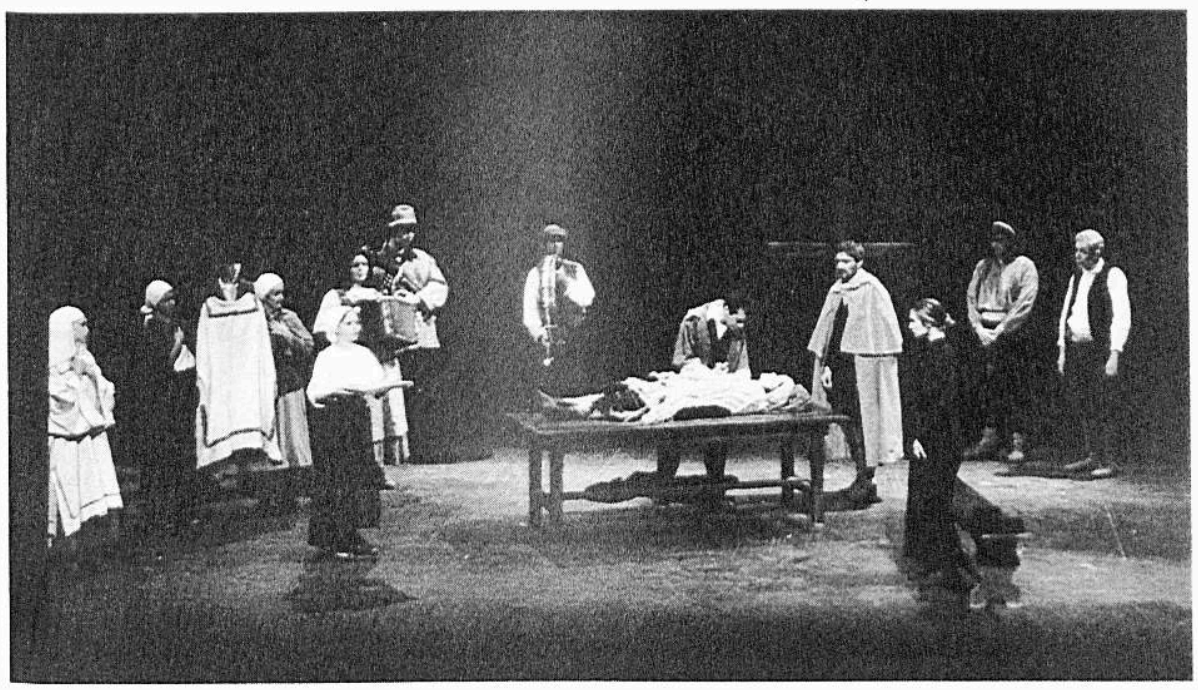

Cliché CAHD

\section{AUTEURS}

\section{ALAIN BERRETA}

Docteur ès Lettres, Université Nancy II 